\title{
THE ELECTROCHEMISTRY OF ORGANIC COMPOUNDS IN APROTIC SOLVENTS- METHODS AND APPLICATIONS
}

\author{
Allen J. Bard \\ Department of Chemistry, University of Texas at Austin, \\ Austin, Texas 78712, U.S.A.
}

\begin{abstract}
The importance of aprotic solvents in studies of the electrochemistry of organic compounds is discussed and a general mechanism for the oxidation and reduction of aromatic hydrocarbons and related substances is presented. The effect of molecular structure on the electrochemical behaviour of organic compounds is illustrated by discussing the relationship between conformations of aryl-substituted anthracenes and dimethylaminophenyl-substituted ethylenes and their electrochemical properties. Techniques and methodology for electrochemical studies in nonaqueous solvents, including solution preparation and cell and electrode design, are briefly reviewed.
\end{abstract}

\section{INTRODUCTION}

The use of anhydrous aprotic solvents, such as $\mathrm{N}, \mathrm{N}$-dimethylformamide (DMF), acetonitrile $(\mathrm{MeCN})$, and dichloromethane $\left(\mathrm{CH}_{2} \mathrm{Cl}_{2}\right)$ as solvents for electrochemical studies started about fifteen years ago. Although many studies of the electrochemistry of organic compounds had been reported up to that time, most were carried out in partially or totally aqueous media. Indeed the second edition of Kolthoff and Lingane's Polarography ${ }^{2}$ has a chapter of only six pages on nonaqueous solvents and in a discussion of the polarography of organic compounds characterizes most reductions of these as irreversible. Although the earliest applications of aprotic solvents were aimed at increasing the solubility of the organic compounds, pioneering studies by Wawzonek, Hoytink, Peover, and their co-workers ${ }^{2}$ demonstrated that the use of these solvents simplified the electrochemical behaviour of organic substances by removing or decreasing the extent of chemical reactions coupled to the electron transfer step. Under these conditions many organic electrode reactions are electrochemically reversible so that correlations of electrode potentials with spectroscopic and molecular orbital (MO) data became possible and a molecular basis of electrochemical reactions of aromatic hydrocarbons was established. Moreover, aprotic solvents provided reduction and oxidation limits beyond those obtainable in aqueous solutions, so that a wider range of potentials became available for electrochemical studies. 
In the last decade a number of new electrochemical techniques have been devised and theoretical treatments for the diagnosis of complex reaction schemes using the data obtained by these techniques have been reported. Modern instrumentation for applying these techniques, based on operational amplifier instrumentation, and more recently on direct data acquisition with digital computers, has also become available. The application of three electrode cells, particularly when used in conjunction with instrumentation employing positive feedback circuits, have made precise measurements possible, even in highly resistive organic solvents. Finally techniques of solvent purification and solution preparation using vacuum line or dry box techniques have decreased even further the effects of side reactions caused by oxygen, water, or other impurities.

This paper is concerned with a brief review of the techniques and methods of studying electrode reactions of organic compounds in aprotic media. A general mechanism for the reduction and oxidation of aromatic compounds is presented and several examples of studies from our laboratories illustrating the effect of structure and solvent on electrochemical behaviour will be described.

\section{TECHNIQUES AND METHODS}

The successful use of aprotic solvents for electrochemical studies requires high purity of both solvent and supporting electrolyte and a system for preparing and maintaining test solutions in a water and oxygen-free environment. We have found that vacuum line techniques have been especially valuable for this purpose. A schematic diagram of a typical vacuum line is shown in Figure 1. This line uses a mechanical vacuum pump and a three stage oil diffusion pump and is generally able to maintain a pressure of about $10^{-5}$ torr. The solvent is purified on a separate line, using procedures described in $\mathrm{Mann}^{3}$ with the last step usually being a vacuum distillation. The purified solvent is stored under vacuum and later transferred under vacuum to the electrochemical cell by distillation or poured into the cell under an inert atmosphere. A typical electrolysis cell of the type designed by Dr Ves Childs and C. P. Keszthelyi in our laboratories is shown in Figure 2. The cell is attached to the vacuum line by a vacuum stopcock-ball joint arrangement. The side-arm allows for solvent pretreatment without affecting the electrodes. The cell is first oriented with its side-arm facing downwards and the sample, solvent and supporting electrolyte are introduced. This is then degassed by the freeze-pump-thaw method by immersing the side-arm in liquid nitrogen and pumping on the solution, closing the stopcock to the cell and allowing the solution to thaw and bubble out any dissolved gas. This cycle is repeated several times. The stopcock can then be closed, the cell removed from the vacuum-line and the main cell body filled by tilting and allowing solution to flow into the auxiliary and test chambers. When a reference electrode, such as an aqueous saturated calomel electrode (S.C.E.), or a working electrode which cannot be subjected to high vacuum are employed, purified helium is led into the cell, and the electrode is then introduced while maintaining a positive helium pressure within the cell. J. T. Maloy has devised a rotating 


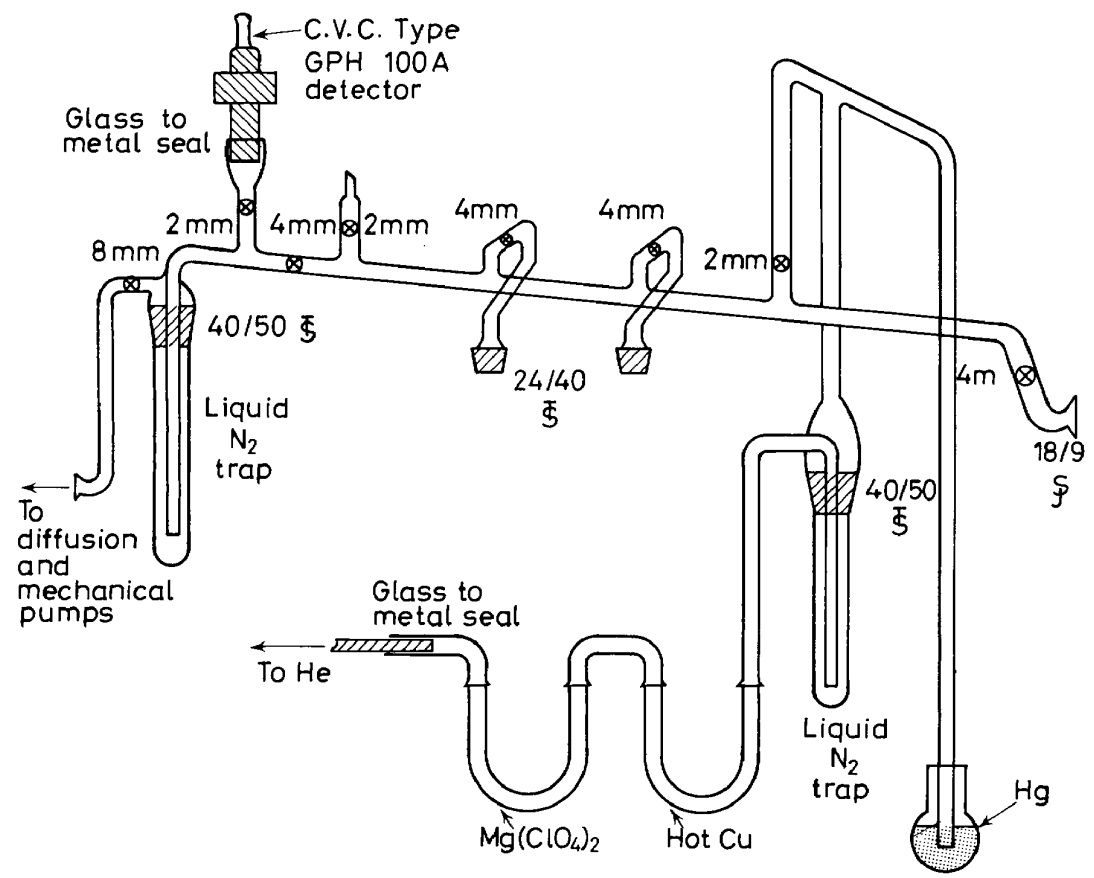

Figure 1. Vacuum line for electrochemical studies. The electrochemical cell attaches to the ball joint at the right. Purified helium can be introduced by the line at the bottom

ring-disc electrode assembly which can be used in such a closed system and which contains the entire motor and tachometer enclosed in the inert atmosphere, thus eliminating the need for a rotating seal (Figure 3).

A number of reference electrodes have been proposed for work in aprotic solvents ${ }^{3}$. The aqueous S.C.E. has probably been used most frequently, and has led to few problems when prepared with an agar salt bridge and introduced into the test solution via a second salt bridge of the appropriate solvent-supporting electrolyte system. For measurements where exact determinations of potential are not required, such as kinetic studies in systems whose potentials have already been characterized, a quasi-reference electrode, such as an unpoised silver wire immersed directly in the test solution, can be employed.

A number of electrochemical techniques are available which have different observation times and which allow measurements of different types and rates of perturbing coupled chemical reactions. The slowest measurements $\left(10^{2}\right.$ to $10^{4}$ seconds) are made with controlled potential coulometry. The conditions of these experiments most closely approximate those of preparative electro-organic chemistry and allow the preparation of rather large amounts of products. The time scale of voltammetric techniques, such as dc polarography, cyclic voltammetry, chronopotentiometry and chronocoulometry, is about $10^{-3}$ to $10^{2}$ seconds. The fastest measurements are made with the rotating disc electrode (R.D.E.) and by ac polarography. The application of 
ALLEN J. BARD

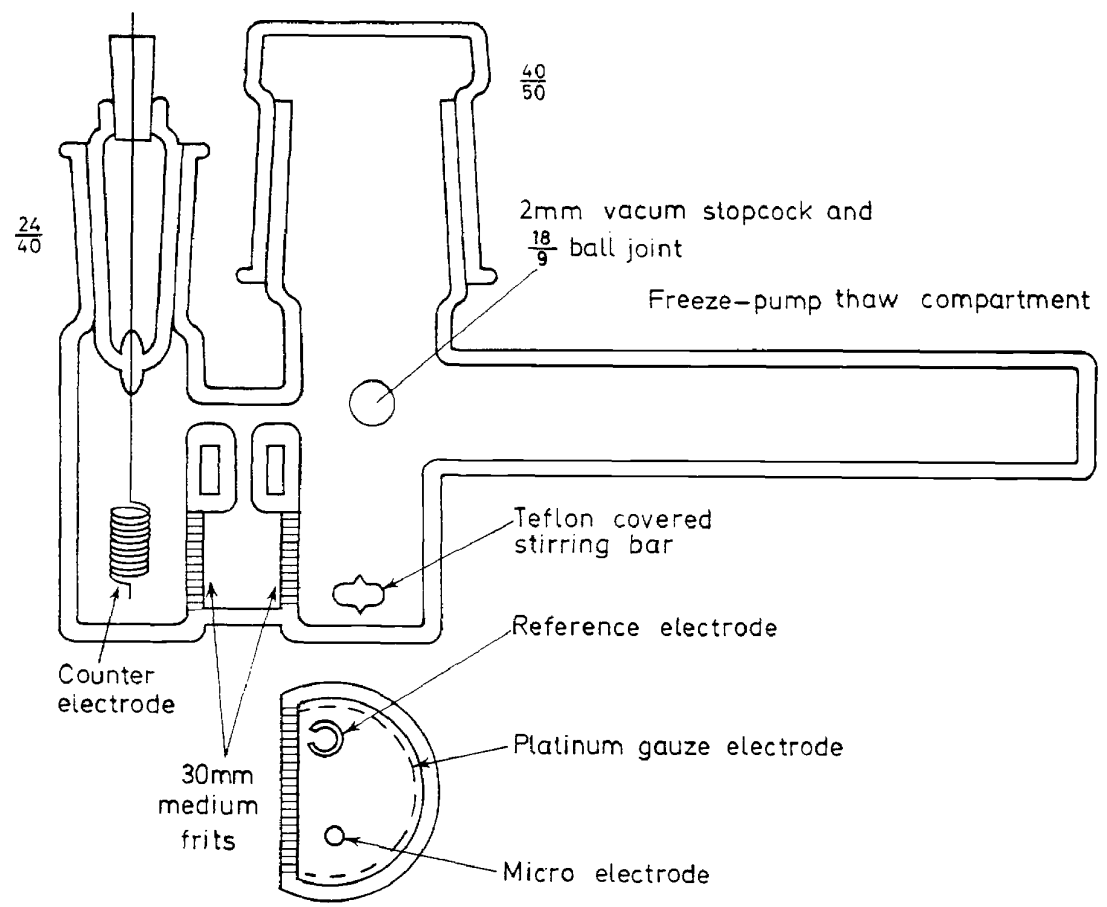

Figure 2. Electrochemical cell for studies in aprotic solvents. The cell attaches to the vacuum line by a ball joint and stopcock. The cell illustrated is for both voltammetric and large scale coulometric studies. A cell with only a single diaphragm can also be employed for voltammetry

digital simulation techniques ${ }^{4}$ allow many complex reaction schemes to be treated. However, distinguishing between different possible schemes requires highly precise measurements over as wide a range of observation times and solution concentrations as possible. The application of in situ spectroscopic techniques, such as electron spin resonance (E.S.R.) spectroscopy, often provides important information about products and intermediates.

\section{GENERAL MECHANISMS FOR REDUCTIONS AND OXIDATIONS}

The general mechanism for the reduction of an organic compound, such as an aromatic hydrocarbon, $\mathbf{R}$, usually starts by the addition of one electron to the lowest vacant molecular orbital (LVMO) to form the anion radical

$$
\mathbf{R}+\mathrm{e} \rightarrow \mathbf{R}^{-}
$$

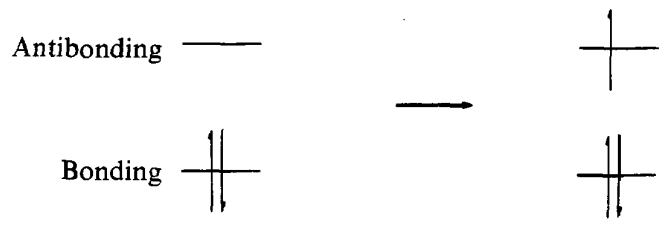




\section{ORGANIC COMPOUNDS IN APROTIC SOLVENTS}

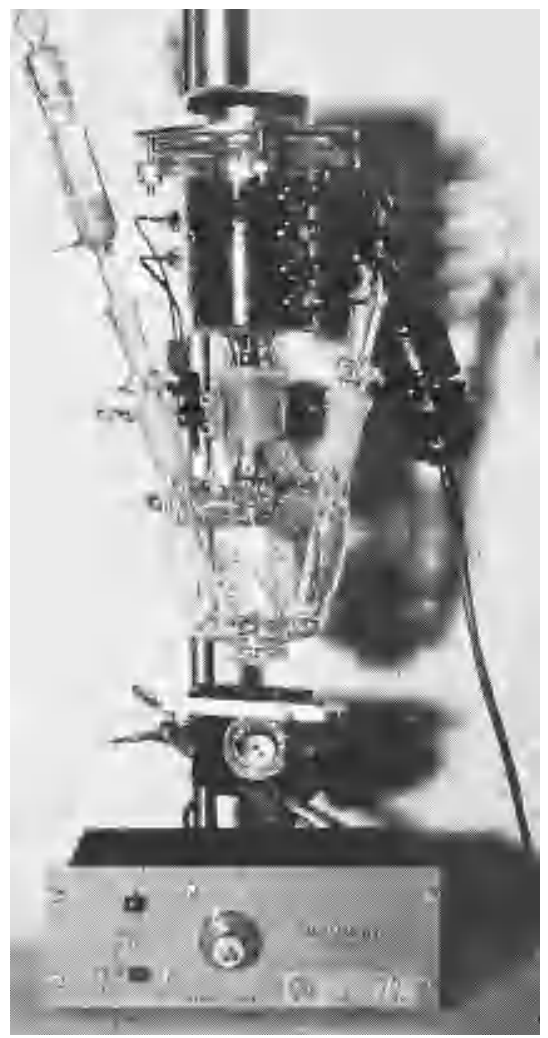

Figure 3. Rotating ring-disk electrode assembly for use in aprotic solvents and closed systems. The entire motor-tachometer assembly is enclosed in the glass envelope. The motor power supply and controller is at the bottom of the picture

This first step is usually rapid and reversible; the potential at which the reduction occurs often correlates very well with molecular orbital calculations of the energy of the $\mathrm{LVMO}^{2}$. The species $\mathrm{R}^{-}$is frequently stable, but it may also undergo several following reactions, as shown below:

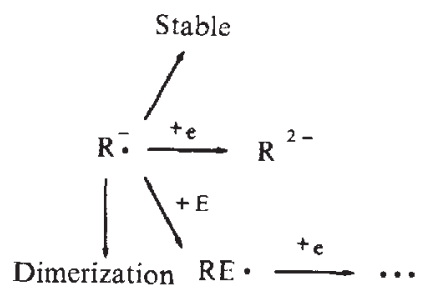

In this scheme $\mathrm{E}$ represents an electrophilic species, such as $\mathrm{H}^{+}$or $\mathrm{CO}_{2}$ which can attack the anion radical and produce a species which is frequently 
easier to reduce than the parent, R. Under these conditions the reactions are classified as ECE reactions (electron transfer, followed by a chemical reaction, followed by a second electron transfer), and may resemble an overall two- or multi-electron transfer reaction. Dimerization is prevalent in molecules such as the substituted ethylenes and may be the prevalent path of the hydrodimerization reaction investigated by Baizer and co-workers ${ }^{5,6}$.

A similar sequence can be written for oxidation reactions. In this case the cation radical is first formed by removal of an electron from the highest occupied molecular orbital (HOMO).

$$
R-e \rightarrow R^{ \pm}
$$
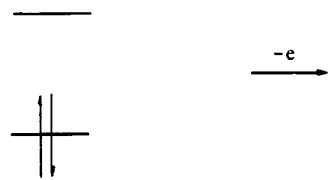

This is also usually a rapid reaction so that the potential at which oxidation occurs correlates well with the calculated energy of the HOMO, although the potentials measured by voltammetry are often perturbed in this case by fast following reactions of the cation radical. The reactions of the cation radical are analogous to those of $R^{-}$.

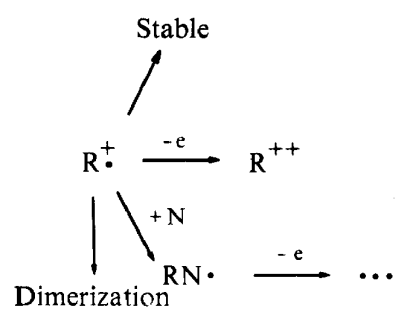

Here $\mathrm{N}$ represents a nucleophilic agent, such as pyridine, hydroxyl ion, cyanide ion, or acetate ion which can attack the cation radical.

The particular aprotic solvent and supporting electrolyte used affects the nature of the overall mechanism in several ways. The overall oxidation and reduction limits are determined by the solvent system. The solvent or impurities often play the role of $\mathbf{N}$ or $\mathbf{E}$ in the above sequences. Water, which is difficult to remove in levels below $1 \mathrm{mM}$ from solvents such as $\mathrm{MeCN}$, probably is a common agent for the attack of cation radicals ${ }^{7}$. Protonation of the anion radical or dianion also often involves the solvent system or supporting electrolyte. Dimerization of the ion radicals is favoured by increases in the dielectric constant of the solvent. On the other hand formation of ion pairs between hydrocarbon ions and counterions from the supporting electrolyte is favoured by small dielectric constants. The extent of solvation of the ions affects the potentials of the corresponding electrode 
reactions and is especially important in the formation of dianions and dications. Solvation is also a factor in the rates of electron transfer reactions of the radical ions and probably of the rate of heterogeneous electron transfer to the parent hydrocarbon.

\section{EFFECT OF STRUCTURE ON ELECTROCHEMICAL BEHAVIOUR}

\section{Conformations of molecules by electrochemistry}

Since the first electron transfer step can be correlated with the position of the LVMO or the HOMO, structural changes which affect the energies of the molecular orbitals also affect the reduction and oxidation potentials. Hence increased conjugation in an aromatic hydrocarbon lowers the LVMO and raises the HOMO, so that both oxidation and reduction of a highly conjugated system occurs more readily. For example benzene is reduced and oxidized with great difficulty ${ }^{8}$. More conjugated hydrocarbon systems are easier to reduce or oxidize; the sequence, in order of increasing ease of electrolysis, is biphenyls, naphthalenes, anthracenes, naphthacenes, etc. This relationship of potential and conjugation has been exploited in our laboratory to determine the conformations of phenyl substituted anthracenes and related compounds. Consider, for example. 9,10-diphenylanthracene (9,10-DPA).

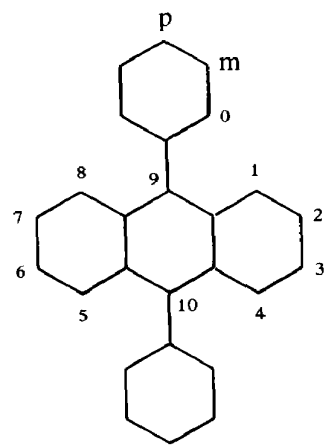

9,10-diphenylanthracene

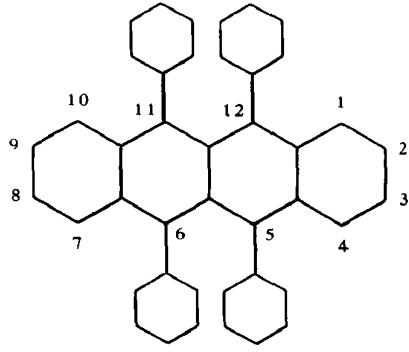

5,6,11,12-tetraphenylnaphthacene

The steric interaction between the hydrogen atoms on positions $1,4,5$, and 8 and the hydrogen atoms on the ortho-positions of the substituted phenyl rings is quite large. so that the phenyl rings are rotated out of the plane of the anthracene nucleii by some angle $\theta$. Previous ESR studies ${ }^{9}$ showed that the angle for $9,10-\mathrm{DPA}$ was about $68^{\circ}$. This value was obtained by fitting the relative hyperfine coupling constants of hydrogen atoms on various locations on the molecule with values calculated by Hückel MO theory for different values of $\theta$. These MO calculations also give the relative energies of the LVMO and HOMO. When the reduction and oxidation potentials of 9,10-DPA were compared to those predicted from MO theory based on the ESR results (employing anthracene and naphthacene to fix the relative scale of potentials), an excellent correlation was obtained ${ }^{10}$. This application 
of electrochemical measurements for the determination of conformations was extended to a number of other related compounds; typical results are given in Table $1^{10,11}$. The trends observed in the $\theta$-value of these compounds

Table 1. Reduction potentials of phenyl-substituted anthracenes and related compounds in DMF and calculated angles, $\theta$, between substitutent group and anthracene nucleus ${ }^{\mathrm{a}}$

\begin{tabular}{lccc}
\hline \multicolumn{1}{c}{ Molecule } & $\begin{array}{c}\mathrm{E}_{\mathcal{t}_{+}} \\
\text {(V. vs. S.C.E.) }\end{array}$ & $\begin{array}{c}\theta \\
\text { (def.) }\end{array}$ & Reference \\
\hline 2-phenylanthracene & 1.872 & 25 & 10 \\
1-phenyl- & 1.878 & 53 & 10 \\
9-phenyl- & 1.863 & 68 & 10 \\
9,10-diphenyl- & 1.835 & 68 & 10 \\
1,10-diphenyl- & 1.787 & $60-70^{\mathrm{b}}$ & 10 \\
1,9-diphenyl & 1.846 & $60-70^{\mathrm{c}}$ & 10 \\
9,10-dinaphthyl- & 1.82 & $70-75$ & 11 \\
5,6,11,12-tetraphenylnaphthacene & 1.410 & 60 & 10 \\
\hline
\end{tabular}

\footnotetext{
a Data for reduction of substances in DMF- $-0.1 \mathrm{M}$ tetra- $n$-butylammonium iodide at mercury electrode.

position 10.

c position 9.
}

is in the expected direction; 2-phenylanthracene, which has a rather weak steric interaction (like that of biphenyl) shows the smallest $\theta$, while the molecules with large steric interactions, such as 9,10-di( $\alpha$-naphthyl)anthracene, show large values of $\theta$. In many of the above cases the electrochemically determined $\theta$-values were checked by ESR spectroscopy, and good agreement was found.

\section{One vs. two electron oxidations}

The question of whether the primary electron transfer involved the removal or addition of one or two electrons was the subject of some controversy in several investigations. It now appears that many apparent simultaneous two-electron transfers actually are ECE reactions. Within the framework of simple Hückel MO theory, the transfer of an electron to the anion radical or the removal of an electron from the cation radical should occur at the same potentials as those at which the ion radicals themselves are formed, since formation of the dianion or dication involves electron addition to, or removal from, the same MO. However, simple MO theory neglects the electron repulsion. Calculations which include these additional repulsion terms indicate the additional energy required to add the second electron is in the order of $5.0 \mathrm{eV}$. The difference between the first and second electron transfers is not that large, however, because the dianion and dication will be more highly solvated ${ }^{12}$ than the radical ions, and they will also tend to form stronger ion pairs or aggregates. These effects tend to greatly decrease the overall energy required to add the second electron, and the usual separation between the first and second electron transfer steps is about $0.5 \mathrm{~V}$. However, geometric changes in the molecule after the addition or removal of one and two electrons can change the orbital energies enough to make the second electron transfer occur more readily than the first. Cases such as this were 


\section{ORGANIC COMPOUNDS IN APROTIC SOLVENTS}

recently investigated by John Phelps in a study of the oxidation of dimethylaminophenyl substituted ethylenes and related compounds ${ }^{13}$. A summary of the electrochemical behaviour of these substances in $\mathrm{CH}_{2} \mathrm{Cl}_{2}-0.2 \mathrm{M}$ tetra-nbutylammonium perchlorate is given in Table 2. The compound 2,2-bis( $p$-N,N-dimethylaminophenyl)-1,1-diphenylethylene (u-TMPE) undergoes

Table 2. Electrochemical data for oxidation of some dimethylaminophenyl-substituted ethylenes $^{13, \text { a }}$

\begin{tabular}{|c|c|c|c|c|c|c|c|}
\hline $\begin{array}{c}\text { Molecule } \\
\text { dimethyl- } \\
\text { aminophenyl }\end{array}$ & $\begin{array}{l}\text { (substitu- } \\
\text { ents) } \\
\text { phenyl }\end{array}$ & $\begin{array}{l}\text { Abbrevia- } \\
\text { tion }\end{array}$ & $\begin{array}{c}\text { Cyclic } \\
\text { Voltammetry } \\
i_{\mathrm{p}} / \mathrm{v}^{\frac{1}{2}} \mathrm{C}^{\mathrm{b}}\end{array}$ & $i_{\mathrm{L}} / C^{\mathrm{c}}$ & $\begin{array}{l}\mathrm{E}_{\frac{1}{2}} \\
\text { (V. vs. S.C.E.) } \\
\text { R.D.E. }\end{array}$ & $\begin{array}{l}\text { Log Plot } \\
\text { Slope } \\
\text { (mV) } \\
\text { Voltammetry }\end{array}$ & $\begin{array}{c}\text { Coulo- } \\
\text { metry } \\
\mathrm{n}_{\mathrm{app}}{ }^{\mathrm{e}}\end{array}$ \\
\hline 1.1 & 2,2 & s-TMPE & $\begin{array}{l}12.8 \\
14\end{array}$ & $\begin{array}{r}8.6 \\
16.2\end{array}$ & 0.578 & 58 & 0.98 \\
\hline 1,2 & 1,2 & $\begin{array}{c}\text { s-TMPE } \\
\text { (cis or trans) }\end{array}$ & & 20.4 & 0.44 & 34 & 2.01 \\
\hline $1,1,2$ & 2 & HMPE & 31 & 19.2 & 0.321 & 36 & 2.02 \\
\hline $1,1,2,2$ & - & OMPE & 32 & 18.0 & 0.160 & 36 & 2.01 \\
\hline \multicolumn{2}{|c|}{$\begin{array}{l}\text { tetra }(p \text {-methoxyphenyl)- } \\
\text { ethylene }\end{array}$} & TAE & 17 & 15 & 0.99 & $\mathrm{f}$ & $\begin{array}{l}0.86^{\mathrm{g}} \\
2.1^{\mathrm{h}}\end{array}$ \\
\hline
\end{tabular}

a The solution was $\mathrm{CH}_{2} \mathrm{Cl}_{2}-0.2 \mathrm{M}$ tetra- $n$-butylammonium perchlorate. The electrode was platinum.

b $i_{\mathrm{p}}=$ anodic peak current $(\mu \mathrm{a}), \mathrm{v}=\operatorname{scan}$ rate $(\mathrm{V} / \mathrm{sec}), \mathrm{C}=$ concentration $(\mathrm{mM})$, electrode area $=0.013 \mathrm{~cm}^{2}$

$i_{\mathrm{L}}=$ limiting current $(\mu \mathrm{A}), C=$ concentration $(\mathrm{mM})$.

Slope of plot of $E$ vs. $\log \left(i_{\mathrm{L}}-i / i\right)$.

- Potential controlled at least $0.2 \mathrm{~V}$ past $\mathrm{E}_{\mathrm{f}}$ (except for TAE), $\mathrm{n}_{\mathrm{app}}=$ number of faradays per mole.

f Slope non-linear (see Figure 6).

Oxidation at $0.95 \mathrm{~V}$ vs. S.C.E. E.S.R. examination of solution shows intense singlet with some superimposed hyperfine structure.

" Oxidation at $1.2 \mathrm{~V}$ vs. S.C.E.

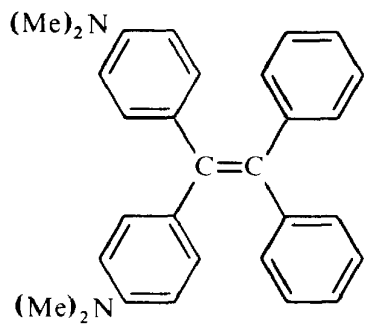

u-TMPE

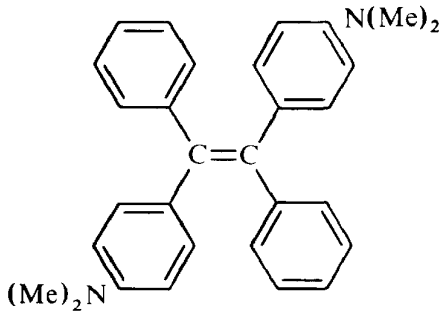

S-TMPE

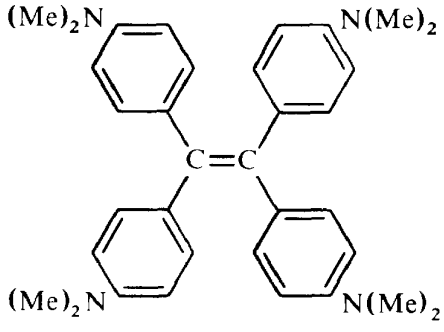

OMPE

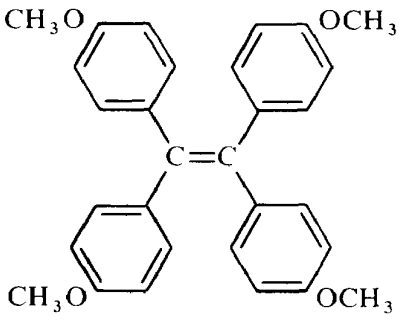

TAE 


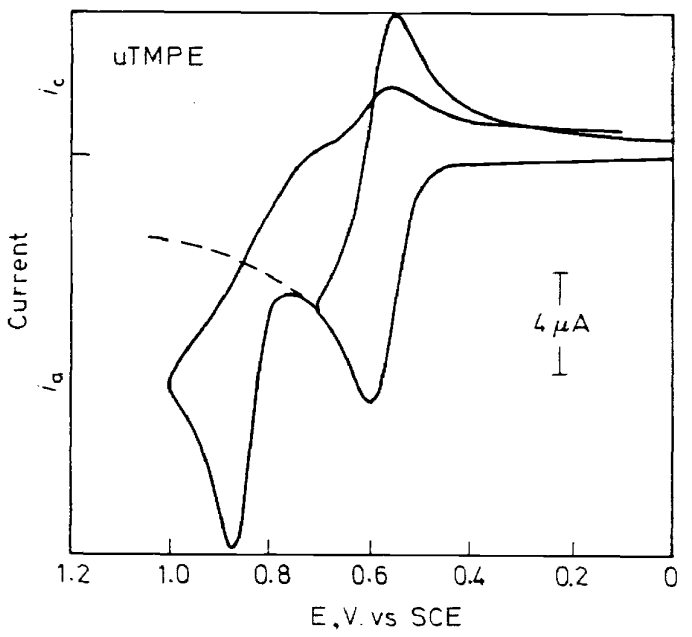

Figure 4. Cyclic voltammetric oxidation of 2,2-bis-( $p$-N,N-dimethylaminophenyl)-1,1diphenylethylene (u-TMPE) at platinum electrode in methylene chloride- $0.2 \mathrm{M}$ tetra- $n$-butylammonium perchlorate

an initial one electron oxidation step at 0.57 V. vs. S.C.E., followed by a second one electron oxidation at $0.85 \mathrm{~V}$. (Figure 4). Similar behaviour is found with $\mathrm{N}, \mathrm{N}, \mathrm{N}^{\prime}, \mathrm{N}^{\prime}$-tetramethyl-p-phenylenediamine. The results of a number of different electrochemical techniques, including cyclic voltammetry, chronoamperometry, rotating disc electrode voltammetry and coulometry all give unequivocal evidence for this scheme ${ }^{13}$. The related compounds, tetrakis( $p$-N,N-dimethylaminophenyl)-ethylene (OMPE), 1,1,2-

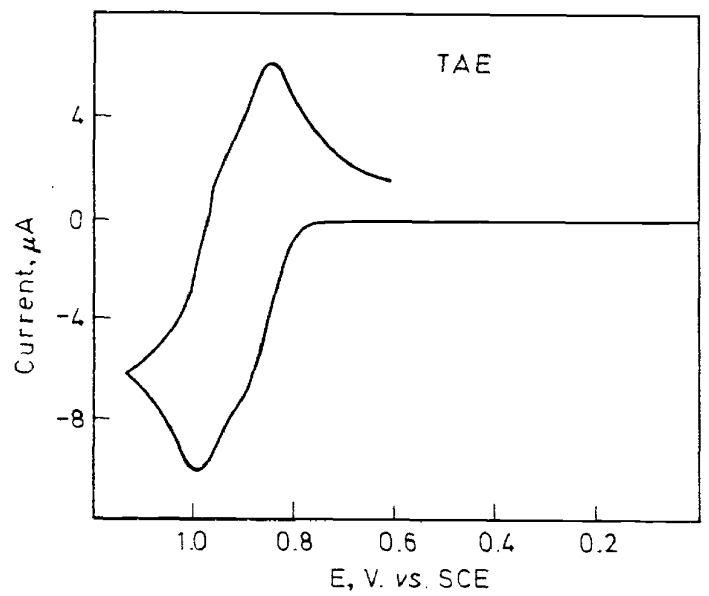

Figure 5. Cyclic voltammetric oxidation of tetrakis-( $p$-methoxyphenyl)ethylene at platinum electrode in methylene chloride $-0.2 \mathrm{M}$ tetra- $n$-butylammonium perchlorate 


\section{ORGANIC COMPOUNDS IN APROTIC SOLVENTS}

tris( $p$-N,N-dimethylaminophenyl)-2-phenylethylene (HMPE), and cis- and trans-1,2-bis( $p$-N,N-dimethylaminophenyl)-1,2-diphenylethylene (s-TMPE) all show behaviour characteristic of a single two-electron oxidation step. For example, the limiting current at a rotating disc electrode for OMPE is about twice that of the first wave of $\mathrm{u}$-TMPE, the anodic peak current in cyclic voltammetry for OMPE is about (2) $)^{\frac{3}{2}}$ that of u-TMPE, analysis of the voltammetric waves shows behaviour attributable to a reversible two electron transfer, and coulometry shows 2.0 faradays consumed per mole of OMPE (Table 2). Interesting intermediate behaviour is shown by tetrakis-( $p$ methoxyphenyl)-ethylene (TAE). The results here are characteristic of two closely spaced single electron transfers. The cyclic voltammetric waves (Figure 5) show some suggestion of two waves, and the value of $i_{\mathrm{p}} / \mathrm{v}^{\frac{1}{2}} \mathrm{C}$ is intermediate between that of a single step one and two electron transfer, as expected from theory ${ }^{14}$. Logarithmic analysis of the current-potential curve (Figure 6) obtained with a R.D.E. shows the curvature expected of two

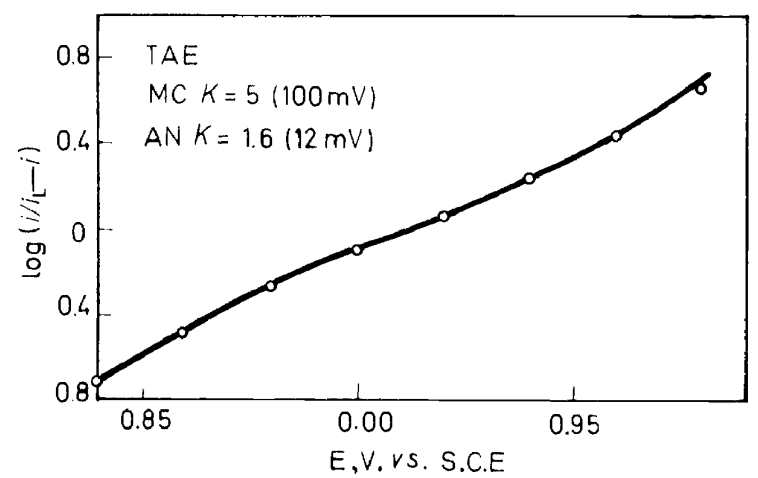

Figure 6. Logarithimic analysis of rotating disc voltammetric wave for oxidation of tetrakis( $p$-methoxyphenyl)ethylene at platinum electrode in methylene chloride- $-0.2 \mathrm{M}$ tetra- $n$ butylammonium perchlorate

closely spaced waves and allows determination of the equilibrium constant. $K$, for the reaction

$$
\mathrm{R}^{++}+\mathbf{R} \rightleftharpoons 2 \mathrm{R}^{+}
$$

The values of $K$ found in $\mathrm{CH}_{2} \mathrm{Cl}_{2}$ and $\mathrm{MeCN}$ are 55 and 1.6 respectively. The smaller value for $K$ in $\mathrm{MeCN}$ is probably caused by greater solvation of the dication by $\mathrm{MeCN}$. The fact that OMPE and related compounds undergo a single direct two electron step can be attributed to changes in geometry and relief of steric strain in the molecules upon oxidation to the dication. Compounds related to the tetraphenylethylenes show considerable steric strain because of interactions of hydrogen atoms on the substituent phenyl rings (Figure 7); this steric strain is relieved by rotation around the C-phenyl bond and by twisting of the $\mathrm{C}-\mathrm{C}$ ethylene bond. Calculations by Dr Ira Goldberg have shown that upon oxidation of these molecules the bond order of the C-phenyl bond increases and that of the $\mathrm{C}-\mathrm{C}$ ethylene bond decreases, so that the molecule would tend to twist as it oxidizes. Thus, if the parent 

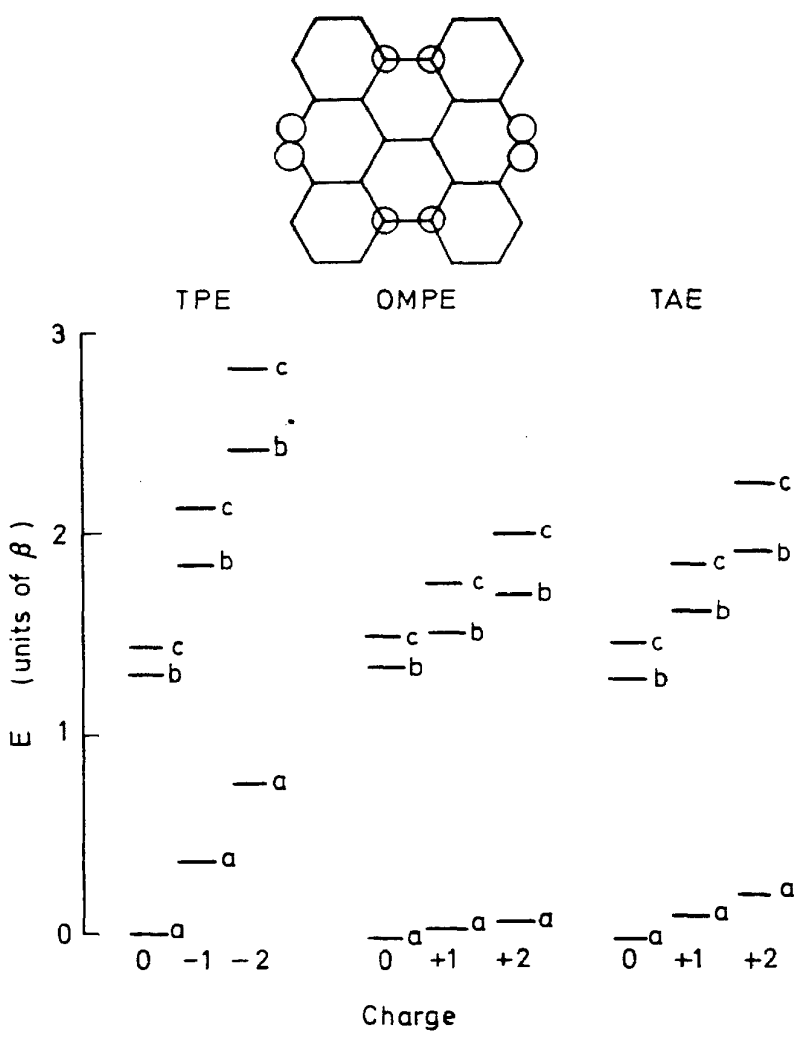

Figure 7. Top: Steric interactions in phenyl substituted ethylene molecules. Bottom: Calculated resonance energies for parent, radical ion, and dianion of tetraphenylethylene (TPE), tetrakis( $p$-dimethylaminophenyl)ethylene (OMPE) and tetrakis-( $p$-dimethoxyphenyl)ethylene (TAE) with following conformations (a) planar; (b) angle about C-Phenyl $=56^{\circ}$, angle about ethylene $\mathrm{C}-\mathrm{C}=18^{\circ} ;$ (c) angle about $\mathrm{C}$-Phenyl $=67^{\circ}$, angle about ethylene $\mathrm{C}-\mathrm{C}=0^{\circ}$

and radical cations are constrained to seek planarity, but the dications can twist and relieve steric strain, the HOMO may move upward in the oxidation process and removal of the second electron may be made easier. Some representative calculations illustrating these effects are shown in Figure 7. These calculations must be considered only in a qualitative sense since the actual conformations of the molecules are not known and relief of steric strain by bond bending and stretching is also possible. A very similar explanation has been invoked by Garst and co-workers ${ }^{15}$ to explain the disproportionation of the tetrapheylethylene anion radical. Additional evidence for the weakening of the $\mathrm{C}-\mathrm{C}$ ethylene bond in the dication is obtained from the following experiment. The s-TMPE molecule can exist in two forms, cis- and trans-, which show essentially identical electrochemical behaviour, but which can be separated and yield distinct nuclear magnetic resonance spectra. Upon controlled potential oxidation of trans- s-TMPE to the dication, followed by reduction back to the parent compound, a 
mixture of both the cis- $^{-}$and trans-forms was obtained. Although the parent compound does not isomerize, the dication isomerizes readily, in agreement with the proposed mechanism.

\section{Structure and reactivity of radical ions}

The structure of the aromatic species also affects the path of reactions coupled to the first or second electron transfer step. For example, the attack of a proton on a radical anion or dianion will generally occur at positions of high electron density ${ }^{16}$. The electron densities on positions 1,2 , and 9 of anthracene are $0.045,0.087$, and 0.184 , respectively, hence protonation would occur in the 9 and 10 positions. For the anion radicals, blocking of these sites by phenyl-groups leads to greater stability of the ions, so that 9,10-DPA anion radical is more stable in DMF than that of anthracene. Moreover, the overall path of the reduction of these compounds depends upon the structure of the species formed upon protonation of the dianion. Cyclic voltammetric data for the reduction of several phenyl anthracenes is given in Table $3^{17}$. Note that 9,10-DPA and 9-phenylanthracene (PA) show only two reduction waves, since protonation in the 9 and 10 positions leaves a system with no

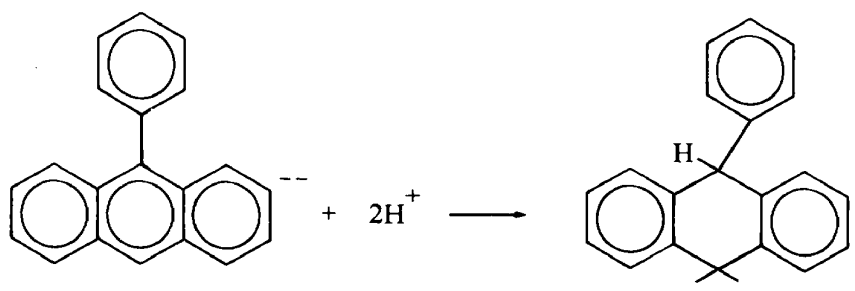

conjugation between the phenyl rings. On the other hand 1,9-DPA and 1,10 -DPA show a third wave at potentials close to those where biphenyl is reduced, since protonation of the dianion leads to a biphenyl-like system.

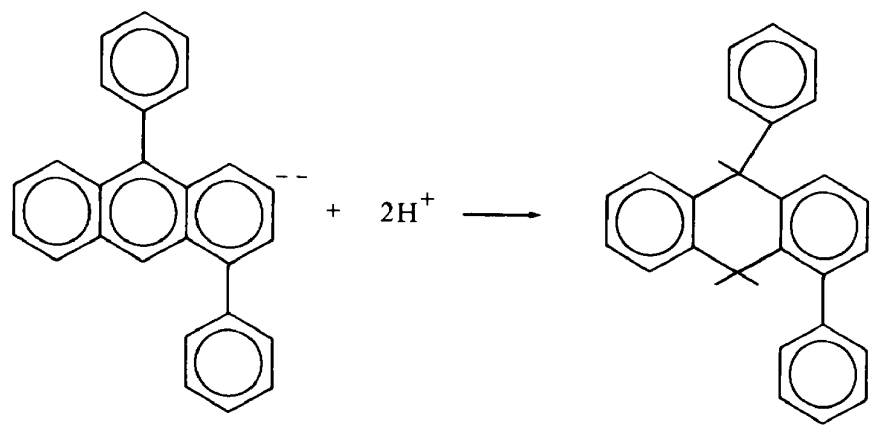

The resistance of cation radicals from attack by nucleophilic species also depends upon the extent to which the positions of high charge density are blocked ${ }^{18}$. Electrochemical studies of the rate constants for the decay of cation radicals of substituted anthracenes in a $\mathrm{CH}_{2} \mathrm{Cl}_{2}-0.2 \mathrm{M}$ tetra-n- 
ALLEN J. BARD

Table 3. Cyclic voltammetric data for the reduction of several phenyl-substituted anthracenes ${ }^{17, a}$

\begin{tabular}{lcccccc}
\hline \multicolumn{1}{c}{ Molecule } & \multicolumn{2}{c}{ Wave I } & \multicolumn{2}{c}{ Wave II } & \multicolumn{2}{c}{ Wave III } \\
\hline 9-PA & $i_{\mathrm{p}} / \mathrm{v}^{\frac{3}{3}}$ & $-\mathrm{E}_{\mathrm{p}_{\mathrm{c}}}^{\mathrm{b}}$ & $i_{\mathrm{p}} / \mathrm{v}^{\frac{1}{2}}$ & $-\mathrm{E}_{\mathrm{pc}}$ & $i_{\mathrm{p}} / \mathrm{v}^{\frac{1}{2}}$ & $-\mathrm{E}_{\mathrm{pc}}$ \\
1,9-DPA & 1.90 & 1.96 & 1.76 & 2.56 & - & - \\
1,10 -DPA & 0.28 & 1.93 & 0.30 & 2.40 & 0.27 & 2.79 \\
& 1.04 & 1.79 & 1.20 & 2.37 & 0.56 & 2.65 \\
\hline
\end{tabular}

a Reduction in DMF - $0.1 \mathrm{M}$ tetra- $n$-butylammonium iodide at hanging mercury drop electrode at scan rate. $\mathrm{v}$, of 0.312 $\mathrm{V}_{/}$sec. $i_{\mathrm{p}}=$ peak current $(\mu \mathrm{a})$. Results are for different concentrations and electrode areas.

${ }^{b} \mathrm{E}_{\mathrm{pc}}=$ cathodic peak potential, in V. vs. S.C.E.

butylammonium perchlorate medium shows that 9,10-DPA and 9,10dimethylanthracene form stable cation radicals. The 9,10-di( $\alpha$-naphthyl)anthracene cation radical is moderately stable ${ }^{11}$, while the cation radical of anthracene is very unstable and undergoes an ECE-type reaction. Double potential step chronoamperometric measurements were used to measure the rate constants for the decay of related radical cations with intermediate stability ${ }^{13}$. For example, 9-PA cation radical decays with a rate constant of about $2.7 \mathrm{sec}^{-1}$. The 1,4,9-triphenylanthracene cation radical in which there is no substitution on the reactive 10 position but where this position is blocked by the phenyl on the 4 position, is more stable and reacts with a rate constant of $0.19 \mathrm{sec}^{-1}$.

\section{Hydrodimerization reactions}

Finally, we might consider some recent work in our laboratory on the hydrodimerization reaction in $\mathrm{DMF}^{6}$. The electroreduction of diethylfumarate (DEF) at a platinum electrode was investigated using cyclic<smiles>CCOC(=O)/C=C/C(=O)OCC</smiles>

DEF

voltammetry, double potential step chronoamperometry, chronocoulometry, and controlled potential coulometry. The mechanism of the reaction was established by comparing experimental chronoamperometric curves with theoretical curves obtained by digital simulation for different possible mechanisms leading to hydrodimers. The mechanism which fits the data best, for a large number of experiments with different DEF and water concentrations, temperature, etc., is one in which the radical anions dimerize and then protonate. The second order rate constant for this dimerization reaction increases from $371-\mathrm{mole}^{-1}-\mathrm{sec}^{-1}$ for nominally anhydrous DMF to $1451-\mathrm{mole}^{-1}-\mathrm{sec}^{-1}$ for DMF containing $500 \mathrm{mM}$ water, apparently without a change in mechanism. 


\section{ORGANIC COMPOUNDS IN APROTIC SOLVENTS}

\section{ACKNOWLEDGEMENT}

The support of this research by the National Science Foundation (GP-6688X) and the Robert A. Welch Foundation is gratefully acknowledged.

\section{References}

1 I. M. Kolthoff and J. J. Lingane. Polarography Interscience, Ch. 5. New York (1952). See also G. Charlot, J. Badoz-Lambling and B. Tremillon. Electrochemical Reactions Ch. 15. Elsevier, Amsterdam (1962).

${ }^{2}$ This work is reviewed by M. E. Peover in Electroanalytical Chemistry Vol. 2. Ch. 1. A. J. Bard, ed., Dekker, New York (1967).

${ }^{3}$ C. K. Mann in Electroanalytical Chemistry Vol. 2, Ch. 2, A. J. Bard, ed.. Dekker, New York (1969).

${ }^{4}$ S. F. Feldberg in ref. 3, Ch. 4.

${ }^{5}$ See for example J. P. Petrovich. M. M. Baizer and M. R. Ort. J. Electrochem. Soc. 116, 743 (1969), and references contained therein.

6 W. V. Childs, J. T. Maloy, C. P. Keszthelyi and A. J. Bard. Paper at American Chemical Society Meeting. Chicago, Ill.. Sept. (1970).

7 See for example R. E. Sioda. J. Phys. Chem. 72, 2322 (1968).

E. J. Majeski, J. D. Stuart and W. E. Ohnesorge. J. Am. Chem. Soc. 90, 633 (1968).

L. R. Faulkner and A. J. Bard. Ibid., p. 6284.

8 T. Osa, A. Yildiz and T. Kuwana. Ibid. 91,3994 (1969).

H. W. Sternberg, R. E. Markby. I. Wender and D. M. Mohilner. Ibid. $\uparrow+191$.

${ }^{9}$ L. O. Wheeler, K. S. V. Santhanam and A. J. Bard. J. Phys. Chem. 70. 104 (1966); 71, 2223 (1967).

10 A. J. Bard, K. S. V. Santhanam. J. T. Maloy, J. Phelps and L. O. Wheeler. Disc. Faraday Soc. 45, 167 (1968).

11 L. S. Marcoux, A. Lomax and A. J. Bard. J. Am. Chem. Soc. 92, 243 (1970).

12 G. J. Hoijtink, E. DeBoer. P. H. Van Der Meij and W. P. Weijland. Rec. trav. chim. 75, 487 (1956).

N. S. Hush and J. Blackledge. J. Chem. Phys. 23, 514 (1955).

L. E. Lyons. Nature 166, 193 (1950).

13 J. Phelps, Ph.D. Dissertation, The University of Texas, 1970.

A. J. Bard and J. Phelps. J. Electroanal. Chem. 25, App. 2 (1970).

14 D. S. Polcyn and I. Shain. Anal. Chem. 38, 370 (1966).

15 J. F. Garst. E. R. Zabolotny and R. S. Cole. J. Am. Chem. Soc. 86. 2257 (1964).

J. F. Garst. J. G. Pacifici, E. R. Zabolotny. Ibid. 88, 3872 (1966).

16 G. J. Hoijtink and J. Van Schooten. Rec. trav. chim. 71, 1089 (1952).

A. Streitweiser. Molecular Orbital Theory for Organic Chemists Wiley, New York, p. 425 et. seq. (1961).

${ }^{17}$ K. S. V. Santhanam and A. J. Bard. Unpublished results, 1968.

18 J. Phelps, K. S. V. Santhanam and A. J. Bard. J. Am. Chem. Soc. 89, 1752 (1967).

L. S. Marcoux, J. M. Fritsch and R. N. Adams. Ibid. 89, 5766 (1967). 